\title{
Network Characterization for Delivering Multimedia-based Learning in Rural Areas
}

\author{
Y. Bandung ${ }^{a, 1}$, Erwin $^{\text {a,2 }}$, Mervin T. Hutabarat ${ }^{\text {b,3 }}$ \\ ${ }^{a}$ School of Electrical Engineering and Informatics, Institut Teknologi Bandung, Jln. Ganesha 10, Bandung 40132, Indonesia \\ ${ }^{\mathrm{b}} \mathrm{ICT}$ Research Center, Institut Teknologi Bandung, Jalan Ganesha 10, Bandung 40132, Indonesia \\ ${ }^{1}$ bandung@stei.itb.ac.id, ${ }^{2}$ erwin.cahyadi@gmail.com, ${ }^{3}$ m.hutabarat@ieee.org
}

\begin{abstract}
Multimedia technology has been contributing much advancement in education sector within the last decade. Digital Learning - Lesson Study (DL-LS) is a lesson study, a learning approach with a target to improve education sector, i.e. to improve teacher quality, which is conducted through the use of multimedia technology. With this technology, open lesson as a phase in the lesson study is conducted in the form of real-time multimedia delivery over Internet between real classroom and virtual classroom, which is usually located in remote area. Nevertheless, conducting multimedia-based learning in rural areas covers several problems due to their limited network resources. Our observation revealed that limited available network bandwidth becomes an important issue in the real-time multimedia delivery, particularly in rural areas. This paper aims to investigate the network characterization for delivering real-time multimedia-based learning in rural areas. Contribution of this paper is a network analysis for multimedia-based learning in rural areas which is presented based-on a simulation study with data support collected from a network test bed.

Index Terms - Internet multimedia technology, quality of service, network characterization, digital learning.
\end{abstract}

\section{Introduction}

We suppose problems in education quality become important issues for government in many developing countries. As a developing country, Indonesia Government through the Ministry of National Education and Culture put the education development as its central agenda. The government aims to increase the access to education and to improve the education quality. Currently, the development has been demonstrated improved access and quality of education even though much remains to be improved [14].

Information and Communication Technology (ICT) Research Center, Institut Teknologi Bandung, has been participating in national agenda of education by conducting a research on improving education quality through the use ICT since 2009. As described in [14], one focus of the research which also aligns with Indonesian Law No 14/2005 on Teacher and Lecturer is how to improve the quality of teachers who play a significant role in the education by using ICT.

ICT is believed as one potential solution to develop teacher professionalism is the use of information and communication technologies (ICTs) [3][4][13]. The educational technologies which are the use of ICTs in the educational field can contribute in education field as follows. First, ICTs will enhance teaching preparation by providing good training materials, facilitating simulations, capturing and analyzing practice teaching, bringing world experience into the training institution, familiarizing trainees with sources of material and support, and training potential teachers in the use of ICTs for teaching process. Second, ICTs open a whole world of lifelong upgrading and professional development by providing courses at a distance, asynchronous learning, and training on demand. ICTs can be revised easily and they can introduce new courses in response to emerging demands. Third, ICTs break the professional isolation many teachers suffer from. With ICTs, they become part of a network with colleagues and mentors, with universities expertise, and with sources of teaching materials.

Conducting a research on quality improvement of teachers, we adopt lesson study [9][12] as one approach in the improving of teacher quality through collaborative learning activities among teachers in a teacher learning community but in modern ways by using ICT. We call the ICT-based lesson study as digital learning-lesson study (DLLS) [14]. One stage of the DL-LS is conducting open lesson in two or more classrooms by applying Internet multimedia technology.

Conducting multimedia-based learning process between two or more classrooms in live mode [14], particularly in rural areas, covers several problems. Research work in [2] reveals several barriers exist on delivering real-time multimedia over rural wireless network, such as limitation of electricity availability, bottleneck of several paths on the wireless network, and the human barriers on the multimedia system operation and maintenance. Moreover, wireless channel characteristics such as shadowing, multipath, fading, and interferences limit the available bandwidth for delivering some services [1]. Therefore, multimedia-based services will face some problem due to the limited available bandwidth in the wireless network. When the available bandwidth became narrow, the audio and video transmission would be disturbed. In a worst-case scenario, the audio and video transmission would be halted and the multimedia contents could not be delivered over the network. It can be summarized that delivering real-time multimedia over wireless network, particularly in rural areas, is still facing a low Quality of Service (QoS) level due to the limitation of the network capacity and its varying characterizations. This impacts to the difficulties on delivering multimedia over the limited network capacity and results in a low quality of audio/video presented in the remote site. 
We summarize that quality of audio/video received in remote site using multimedia delivery over Internet is affected by the available network resources or the QoSrelated characterization of the network (for example: network bandwidth, end-to-end delay, and packet loss rate). This research aims to investigate the characterization of network which is used to deliver real-time multimedia-based learning consist of audio/video streams in an online open lesson. In this research, we focus on the investigation of network parameters such as bandwidth capacity, end-to-end delay, and packet loss rate for the delivery on multimedia streams.

The rest of this paper is organized as follows. In section 2 , we present related works on Internet multimedia delivery technology and on the use of multimedia delivery technology for education. In section 3, we describe network measurements on our testbed of DL-LS in Cianjur, West Java Province of Indonesia. In section 4, we describe our experiments on delivering multimedia streams over existing network condition through a simulation study. The conclusion of the research is presented in section 5 .

\section{Related Work}

Multimedia communication over Internet becomes a new technology in modern life in this information era. In education, Internet multimedia technology can support and facilitate a distance learning [5][11], which is a learning process followed by students in real classroom as well as in virtual classrooms and delivered by a model teacher in real classroom.

As described in [14], one of multimedia applications in this sector can be found on the implementation of DL-LS as part of learning processes that involves students in one real classroom as well as those in one/more remote classrooms. Multimedia-based contents in the form of audio, video, or data streams that are sent from end-systems in the real classroom, received by end-systems and presented to the students in the remote classroom, will bring the students into learning experience as if they are in a real classroom with real teacher. For interactivity in the learning process that allows long-distance discussion between teacher and the students, the multimedia system is configured to allow twoway communication simultaneously between two participating end-systems. This scenario means delivering rich multimedia contents between two or more participating end-systems over the network.

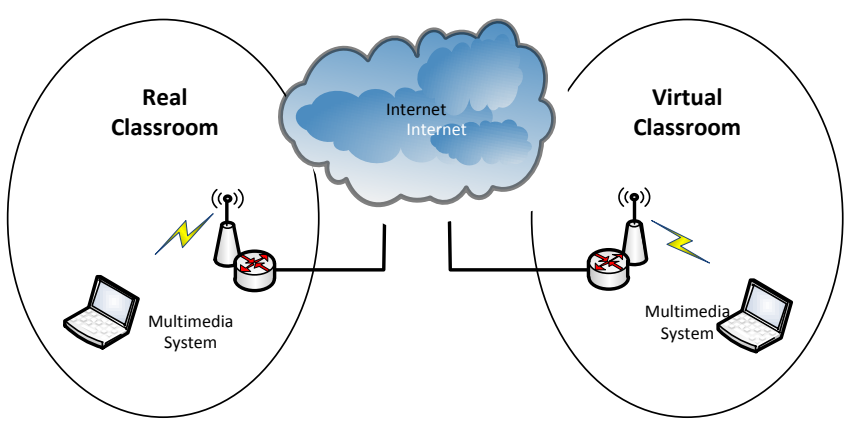

Fig. 1 Network configuration for delivering multimedia-based lesson in DL-LS
Figure 1 illustrates typical network configuration for conducting ICT-based open lesson in network testbed in Cianjur. There are two types of classroom in open lesson scenario: i) real classroom where students conduct a learning process with model teacher, ii) virtual classroom where students follow learning instruction from model teacher in real classroom. A multimedia system is deployed in each classroom to serve multimedia generation-presentation as well as multimedia exchange to/from other classroom. Each network in each classroom is connected to Internet cloud through dial-up connection therefore two networks are connected each other.

\section{Testbed Network Measurement}

In this section, we describe our measurement results of testbed network in Cianjur which is used for conducting ICT-based open lesson. The measurement is focused in one classroom with objective to measure its network performance. In this research, we assume the other classroom will have similar network performance and therefore we did not measure network performance in this classroom.

Important parameters we investigated in this research are bandwidth of the network, end-to-end delay, and packet loss rate (PLR). To collect the network bandwidth and packet loss rate information we used Iperf network performance measurement tool and to measure end-to-end delay we used a popular Ping application.

a. Bandwidth measurement

In our measurement scenario, we measured network bandwidth in a network path between a host in a classroom in Cianjur and a host in ITB campus in Bandung. The distance of two sites is around $60 \mathrm{~km}$ of distance. Sending 1.25 MBytes of UDP datagram in duration 10 second using Iperf, bandwidth of the network is $1.05 \mathrm{Mbits} / \mathrm{sec}$ or $1.05 \mathrm{Mbps}$. After several attempts with different parameters result in similar bandwidth capacity, we summarize that the network bandwidth in the classroom is $1.05 \mathrm{Mbps}$. In this research, we assume the other classroom has similar bandwidth capacity which is $1.05 \mathrm{Mbps}$.

b. End-to-end delay measurement

As in the bandwidth measurement scenario, we measure end-to-end delay in a network path between a host in a classroom in Cianjur and a host in ITB campus in Bandung. Using Ping application, round trip time (RTT) in the network path we measured is $485 \mathrm{~ms}$. From this information, the end-to-end delay in the network path is half of the RTT $=242.5 \mathrm{~ms}$. We calculate the total endto-end delay as a sum of end-to-end delay of network path between a classroom and ITB campus and end-toend delay of network path between ITB campus to the other classroom. We assume the total end-to-end delay $=2 \mathrm{x}$ end-to-end delay of a network path $=2 \times 242.5 \mathrm{~ms}$ $=485 \mathrm{~ms}$. 


\section{c. Packet loss rate measurement}

Packet loss rate parameter of the testbed network was derived from the use of Iperf application. Similar with above measurement scenario to collect bandwidth capacity and end-to-end delay information, we measure packet loss rate of UDP packet delivery in a network path between an host in a classroom in Cianjur and an host in ITB campus in Bandung. Configuring UDP buffer size to 256 Kbyte and sending 893 datagrams with size 1470 byte per datagram in 10 second, 147 datagrams were lost. Hence, the packet loss rate for the UDP delivery is $16 \%$.

\section{Multimedia Delivery over Testbed Network}

In this section, we describe our efforts in network simulation of multimedia delivery over existing network condition as described in the preceding section. For simulating our model, we used OMNeT++ IDE Version 4.4 [10]. The model is also based on an open-source INET Framework for OMNeT++ simulation environment [6]. In this study, we build a simulation model for simultaneously audio and video delivery as a one-way communication system.

Our simulation model is based on the network configuration as drawn in Fig. 1. In the model, each multimedia system is connected to an access point IEEE $802.11 \mathrm{~g}$ that works on carrier frequency $2.4 \mathrm{GHz}$ and data rate up to $54 \mathrm{Mbps}$. The access point is connected to a router via Ethernet link with maximum data rate $100 \mathrm{Mbps}$. The router acts an Internet gateway to Internet cloud via ADSL link namely dialUp connection which applies Point-to-Point Protocol (PPP). The dialUp connection is derived from DatarateChannel with data rate $525 \mathrm{kbps}$. This data rate is derived from the bandwidth capacity of $1.05 \mathrm{Mbps}$ which is divided by 2 . In the real open lesson, the multimedia delivery is transmitted in two-way communication system (duplex), but in this simulation study we transmit the multimedia streams in one-way communication system. Therefore, we assume the bandwidth capacity in each site to deliver multimedia is $525 \mathrm{kbps}$ and to receive multimedia is $525 \mathrm{kbps}$.

According to the delay measurement, the end-to-end delay between two multimedia system is $485 \mathrm{~ms}$. We divide the end-to-end delay into three parts as follows: i) end-toend delay for dialUp connection between a multimedia system in site 1 to Internet cloud, ii) end-to-end delay inside the Internet cloud, and iii) end-to-end delay for dialUp connection between a multimedia system in site 2 to Internet cloud. Assume the Internet cloud is a high speed network, we choose the end-to-end delay inside the Internet cloud is $35 \mathrm{~ms}$. We divide the rest of end-to-end delay for the two dialUp connections, therefore each dialUp connection has $225 \mathrm{~ms}$ of end-to-end delay. In the NED file of our network model, we set Bit Error Rate (BER) of the dialUp connection to $10^{-5}$.

In the following part, we will describe the setting of applications that are implemented on each multimedia system. For delivering multimedia stream which is consist of audio and video streams, we define two applications as follows:
- Delivery of audio. For the audio delivery, we apply Voice over Internet Protocol (VoIP) applications of the INET framework namely VoIPSimpleSender which is installed in a multimedia system in first site and VoIPSimpleReceiver which is installed in a multimedia system in second site. Configuring the audio applications, we assume $100 \mathrm{kbps}$ of audio stream is delivered between multimedia systems. We configure the talkPacketSize parameter to 100 byte and packetizationInterval to $8 \mathrm{~ms}$.

- Delivery of video. For the video delivery, we apply UDP applications of INET framework namely UDPVideoStreamSvr which is installed in a multimedia system in the first site and UDPStreamVideoCli which is installed in a multimedia system in the second site. We choose bit rate of the video stream to $500 \mathrm{kbps}$ and based on this assumption we sent 1024 byte video packet every 0.016 second. Therefore, we set packetLen $=$ $1024 \mathrm{~B}$ and sendInterval $=0.016 \mathrm{~s}$. We assume the video packet is sent for duration 100 second and then we can set the video size to $6.25 \mathrm{MB}$.

Beside the multimedia streams we described above, we apply background traffic to approach the real condition in our testbed. The background traffic is Internet traffic generated by other end-systems in our network testbed which is not related with operational of the open lesson. In order to guarantee the QoS of audio/video delivery for open lesson, we need data rate for the background traffic is very small and there will be enough bandwidth capacity on the network to deliver tha audio/video streams.

For the background traffic, we assume UDP traffic and apply UDPBasicApp UDP application modules in both sites. As the configuration of the modules in Omnetpp.ini file, we assume the data rate for the background traffic is $256 \mathrm{kbps}$. By setting the messageLength parameter to 512 byte, then we set the sendInterval parameter to 0.016 second. Since our simulation is run as long as 100 second, we also set the stopTime of the background traffic to 100 second. It means the background traffic is presented every time.

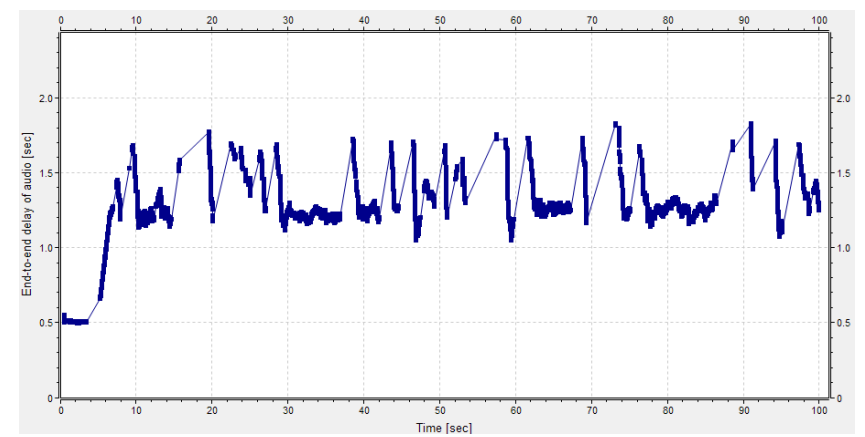

Fig. 2 End-to-end delay of audio delivery

In the next part, we will describe results of the simulation. Firstly, we observe end-to-end delay of the audio delivery. As shown in Fig. 2, the end-to-end delay for the audio is varied around 1.0 second to 2.0 second. According to ITU-T Recommendation G.114 [8], this end-to-end delay is quite high because the accepted end-to-end delay for realtime audio communication should be less than $400 \mathrm{~ms}$. 
Secondly, we observe end-to-end delay of the video delivery. As shown in Fig. 3, the end-to-end delay for the video is varied around 1.0 second to 2.0 second. According to ITU-T Recommendation G.114 [8], the delay for the realtime video communication is quite high since the standard recommend the amount of end-to-end delay for such communication should be less than $400 \mathrm{~ms}$.

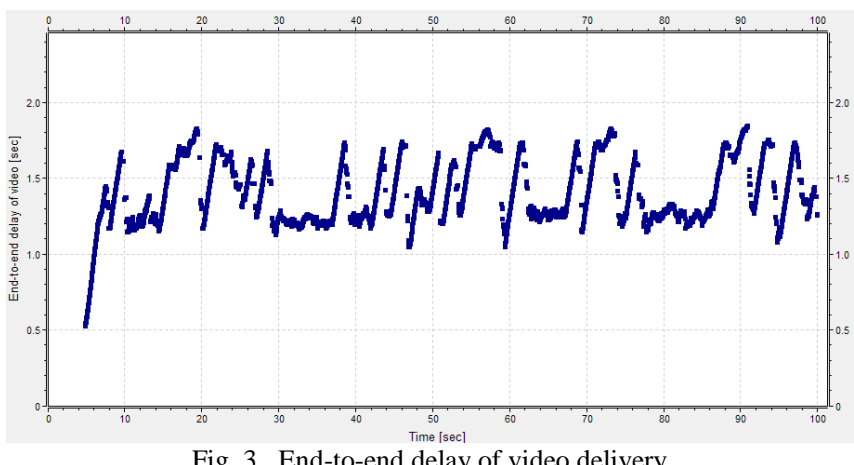

Thirdly, we observe packet loss rate of the audio delivery. As shown in Fig. 4, the packet loss rate for the audio delivery is varied between 0.4 to 0.8 with mean value 0.467 or $46.7 \%$. According to ITU-T Recommendation G.1010 [7], the packet loss rate should be less than $3 \%$ for medium audio in conversational voice application. Based-on this recommendation, the audio delivery in our scenario over existing network performance is unacceptable.

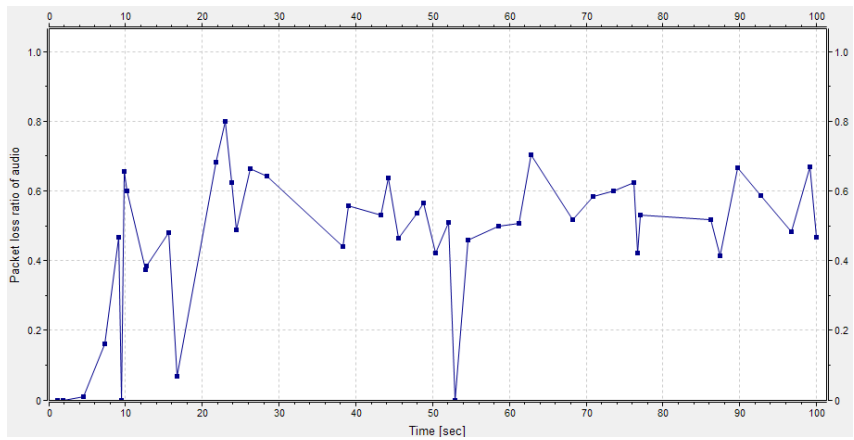

Fig. 4 Packet loss rate of audio delivery

Fourthly, we observe packet loss rate of the video delivery. Sending 5840 datagrams with size 1024 byte per datagram in 100 second, 2374 datagrams were lost in that video delivery. Hence, the packet loss rate of the video delivery is 0.407 or $40.7 \%$. According to ITU-T Recommendation G.1010 [7], the packet loss rate should be less than $1 \%$ for medium video in videophone application. Based-on this recommendation, the video delivery in our scenario over existing network performance is unacceptable.

\section{Conclusions}

In this paper, we have described our observation for existing network performance in our testbed which is used to deliver real-time multimedia streams in ICT-based open lesson between real classroom and virtual classroom in remote site. We collected several network parameters as follows: i) network bandwidth capacity is $1.05 \mathrm{Mbps}$, ii) end-to-end delay is $485 \mathrm{~ms}$, and iii) packet loss rate for a UDP datagrams delivery is $16 \%$. Based-on the existing network condition, we simulated audio/video delivery in OMNeT++/INET Framework and the results described unacceptable quality for both of audio and video. Hence, it is needed further research works on how to guarantee the QoS for multimedia streams in limited network resources.

\section{Acknowledgments}

This research is supported by Riset Unggulan Institut Teknologi Bandung which is conducted in ICT Research Center - Institut Teknologi Bandung and supported by Hibah DIKTI which is conducted in Information Technology Research Group - Institut Teknologi Bandung.

\section{References}

[1] A. Ksentini, M. Naimi, and A. Gueroui, "Toward an improvement of H.264 video transmission over IEEE 802.11e through a cross-layer architecture", IEEE Communications Magazine, Jan. 2006.

[2] A. A. Nugraha, B. Yonathan, Y. Bandung, A. Z. R. Langi, "Tantangan dalam implementasi layanan digital learning pedesaan: Studi kasus jaringan testbed Keerom-Papua," Prosiding Konferensi dan Temu Nasional Teknologi Informasi dan Komunikasi (TIK) untuk Indonesia, Bandung, 5-7 May, 2010.

[3] A. Z. R. Langi, D. H. Widyantoro, Y. Bandung, G.A. P. Saptawati, and Liliasari, "ICT-based approaches for improving the quality of primary education in rural areas," Proceedings of International Conference on Rural Information and Communication Technology, Bandung, 17-18 June, 2009.

[4] C. Elston, Using ICT in the Primary School, 1st ed. London: Sage, 2007.

[5] G. Agosti, "Distance education in the era of internet," in Developing Regional Communities with Information and Communication Technology, S. Marshall, W. Taylor and X. Yu, Eds. Hershey, PA: Idea Group Reference, 2006, pp. 199-204.

[6] INET - A framework for OMNeT++ simulation environment. [Online]. Available: http://inet.omnetpp.org (Access date: Feb. 2014).

[7] ITU-T Rec. End-User Multimedia QoS Categories, ITU-T Std. G.1010, 2001.

[8] ITU-T Rec. One-Way Transmission Time, ITU-T Std. G.114, 2003.

[9] Lesson Study di Jur. Pendidikan Kimia (n.d.). Retrieved from http://kimia.upi.edu/utama/lessonstudy/lsjurusan.htm. (Accessed: 9 November 2013).

[10] OMNeT++ - A discrete event network simulator. [Online]. Available: http://www.omnetpp.org (Access date: Feb. 2014).

[11] S. Naidu, E-Learning: A Guidebook of Principles, Procedures, and Practices, 2nd Revised Edition, New Delhi: The Commonwealth Educational Media Center for Asia, 2006.

[12] T. Suratno, "Teacher learning through Lesson Study: Lessons learnt from a School Improvement Program in an Indonesian Primary School". Paper presented at AARE (Australian Association for Research in Education) International Conference. Melbourne, November 28-December 2, 2010. Retrieved from http://www.aare.edu.au/10pap/2507Suratno.pdf.

[13] W. D. Haddad and A. Draxler, Technologies for Education: Potentials, Parameters, and Prospects, Paris: United Nations Educational, Scientific and Cultural Organization (UNESCO), 2002.

[14] Y. Bandung, A. Z. R. Langi, and M. T. Hutabarat, "Digital learninglesson study (DL-LS) for teacher learning community," in Proc. Joint International Conference on Rural Information and Communication Technology and Electric-Vehicle Technology (R-ICT'13 and ICEVT'13), Bandung, Indonesia, November 2013.

[15] Y. Bandung and A. Z. R. Langi, "Implementing ICT in Primary School in Keerom-Papua", Proc. of International Conference on Telematics System, Services, and Applications (TSSA), Bali, October 2011. 